\title{
O potencial de Florianópolis como cidade criativa.
}

\author{
The potential of Florianópolis as a creative city.
}

BERLATO, Larissa Fontoura; Mestranda; Universidade Federal de Santa Catarina - NAS Design; lari.berlato@gmail.com

FIGUEIREDO, Luiz Fernando Gonçalves de; Doutor; Universidade Federal de Santa Catarina - NAS Design; Iffigueiredo2009@gmail.com

FIALHO, Francisco Antônio Pereira; Doutor; Universidade Federal de Santa Catarina fapfialho@gmail.com

\section{Resumo}

As necessidades da sociedade atual na transição em grande parte provocada pela globalização fazem com que cresça o interesse pelos conceitos de economia criativa e cidade criativa, em função dos seus potenciais nos aspectos sociais, culturais e econômicos. O conceito de cidade criativa se assenta sobre a relação entre a criatividade, o simbólico e a economia (HOWKINS, 2002) promovendo revitalização cultural, participação social e apoio financeiro às indústrias culturais e áreas afins. Este estudo visa identificar o potencial de Florianópolis como cidade criativa; para tanto, divide-se em três etapas: em um primeiro momento faz a revisão sobre os temas, para logo a seguir verificar os dados relativos a Florianópolis e finalmente, analisar a relação entre os temas abordados, identificando as competências de Florianópolis como cidade criativa por meio do modelo 3Ts (Tecnologia, Talento e Tolerância) de classificação das cidades criativas de Florida (2011).

Palavras Chave: criatividade; economia criativa; cidade criativa e classe criativa.

\begin{abstract}
The needs of today's society in the transition largely provoked by globalization increase interest in the concepts of creative economy and creative city, in terms of its potential in social, cultural and economic aspects. The concept of a creative city is based on the relation between creativity, symbolism and economics (HOWKINS, 2002), promoting cultural revitalization, social participation and financial support to cultural industries and related areas. This study aims to identify the potential of Florianópolis as a creative city, for it is divided in three stages: at first it reviews the themes, then verify the data related to Florianópolis and finally, analyze the relationship between the themes, identifying Florianópolis's competences as a creative city through the 3Ts model (Technology, Talent and Tolerance) of the classification of Florida's (2011) creative cities.
\end{abstract}

Keywords: creativity; creative economy; creative city and creative class. 


\section{Introdução}

Em um mundo globalizado, o apelo a criatividade tem ultrapassado fronteiras e culturas, e é reconhecida como importante competência para enfrentar os desafios do século XXI (RUNCO, 2004). A economia atual é movida pela criatividade humana, essa capacidade de inovar é fator determinante de vantagem competitiva. A criatividade é multidimensional, generalizada e contínua, estamos sempre revendo e aprimorando cada produto, cada processo e cada atividade imaginável, e integrando-os de novas maneiras. Além disso, a criatividade tecnológica e econômica é fomentada pela criatividade cultural e interage com ela (FLORIDA, 2011).

As cidades são fatores centrais da transformação, enquanto eixos da economia global, salientando o seu papel no desenvolvimento econômico baseado no talento, ou seja, as cidades concentram maior parte da população mais qualificada, formada, criativa e empreendedora (OCDE,2012). O conceito de cidade criativa tem crescido em interesse e descreve um complexo urbano onde são desenvolvidas atividades culturais que contribuem para o seu funcionamento a nível social e econômico. De acordo com o British Council (2010) existem cinco razões para se realizar o trabalho de verificação dos níveis de criatividade de uma cidade ou região: (1) levantar um perfil das indústrias criativas; (2) aprender mais sobre esse setor dinâmico e sua evolução; (3) preparar-se para crescimento futuro; (4) engajar líderes em questões de políticas públicas que afetem as indústrias criativas tais como revitalização urbana, desenvolvimento rural e (5) coesão social.

As cidades criativas têm tendência a construir fortes infraestruturas sociais e culturais, terem fortes concentrações de emprego relacionado com a criatividade e serem atrativas para investimentos devido as suas bem estabelecidas estruturas artísticas e culturais. Para que uma urbe seja criativa faz-se necessário infraestruturas que vão muito para além do hardware. Além de uma estrutura física, a cidade deve ter mão-de-obra altamente qualificada e flexível, pensadores, criadores, capacidade para oferecer espaço às personalidades dissidentes, meios de comunicação sólidos e uma cultura empreendedora, aplicada a fins econômicos e sociais (ONU, 2010).

A capital de Santa Catarina, Florianópolis, foi eleita a $1^{\text {a }}$ cidade brasileira em Capital Humano, a $2^{a}$ em Inovação e a $3^{a}$ em acesso a capital (ICE, 2016). Este resultado se deve em grande parte em função de sua alta qualidade de recursos humanos; grande quantidade de instituições de ensino superior, como UFSC, UDESC, IFSC e diversas instituições privadas; de incubadoras como CELTA e MIDI Tecnológico, além de centenas de empresas de tecnologia e parques tecnológicos como Alpha e Sapiens Parque. Este estudo tem como objetivo analisar o potencial da cidade de Florianópolis como cidade criativa.

\section{Procedimentos Metodológicos}

Essa pesquisa é exploratória e como procedimento metodológico foram realizadas uma revisão literária e uma análise acerca dos pressupostos teóricos que balizam as temáticas que envolvem criatividade, economia criativa, cidade criativa e classe criativa. $O$ delineamento desse estudo foi feito por meio de uma pesquisa bibliográfica em artigos científicos publicados em periódicos, teses, dissertações e livros. Em um segundo momento foi realizada uma pesquisa sobre a situação atual da cidade de Florianópolis através de dados processados por órgãos públicos e privados.

Esta pesquisa divide-se em três etapas: em um primeiro momento faz a revisão sobre os temas, para logo a seguir verificar as informações sobre Florianópolis e finalmente, analisar a 
relação entre os temas abordados, identificando as competências de Florianópolis como cidade criativa por meio do modelo 3Ts de classificação das cidades criativas de Florida (2011).

\section{Fundamentação teórica}

\subsection{Criatividade e Design}

A criatividade é um conceito complexo, de difícil definição, dependendo do âmbito de aplicação, e que pode ser abordado a partir de inúmeras perspectivas diferentes. De acordo com Vygotsky (1987), a "atividade criadora" é algo capaz de gerar o novo, sendo visto aos olhos do "mundo exterior". Criatividade é o processo de tornar-se sensível a problemas, deficiências, lacunas no conhecimento, desarmonia; identificar a dificuldade, buscar soluções, formulando hipóteses a respeito das deficiências; testar e retesar estas hipóteses; e, finalmente, comunicar os resultados (TORRANCE, 1972).

A criatividade não está somente na ideia, no processo ou na habilidade do artista, nem no domínio de prática e tampouco no grupo de juízes, mas sim numa interação entre todas essas dimensões (GARDNER). Csikszentmihalyi (2013) defende que para criar é importante não só um conhecimento aprofundado acerca do domínio em que se cria, mas também um conhecimento multidisciplinar - e isto não só considerando a alta criatividade como também a criação no dia-adia. $\mathrm{O}$ ato de criar mostra-se como um fenômeno multifacetado, o qual mistura elementos referentes à pessoa (personalidade e pensamento) e ao ambiente (clima psicológico, valores e normas da cultura e oportunidades para expressão de novas ideias) (ALENCAR, 1995). Eysenck (1999) sugere a existência de três conjuntos de variáveis que fazem parte do que se considera criatividade: variáveis cognitivas (inteligência, conhecimento, habilidades técnicas, talentos especiais), variáveis ambientais (fatores político-religiosos, fatores culturais, fatores sócioeconômicos, fatores educacionais) e variáveis de personalidade (motivação interna, confiança, não-conformismo, criatividade traço).

A criatividade é essencial para a maneira como vivemos e trabalhamos hoje. Segundo Florida (2011) não é surpreendente que a criatividade tenha se tornado o bem mais estimado de nossa economia, afirmando que a economia atual é movida pela criatividade humana, não se limitando à criação de inventos espalhafatosos, novos produtos ou novas empresas. A criatividade é multifacetada e multidimensional, não se limita à inovação tecnológica ou a novos modelos de negócios; o processo criativo é social, não só individual: logo, requer formas de organização. A principal força propulsora da economia do conhecimento é a criatividade humana, por isso ela tornou-se agente central também na vida em sociedade, promovendo constantemente o aprimoramento dos produtos, processos e atividades relacionadas à vida humana (FLORIDA, 2011).

Criatividade é a geração de novas ideias - sejam elas um novo olhar sobre problemas existentes ou a descoberta de novas oportunidades. Inovação é a exploração de novas ideias. Design é o elo que une criatividade e inovação - o elemento que molda as ideias a fim de torná-las proposições práticas e atraentes para usuários e clientes. (COX, 2005 apud BEST, 2012, p.168).

O Design como atividade criativa que é contribui na descoberta e investigação das relações estruturais, organizacionais, funcionais, expressivas e econômicas, com o intuito de aumentar a sustentabilidade global e a proteção ambiental (ética global); prover benefícios e liberdade a toda comunidade humana, individual e coletiva, usuários finais, produtores e protagonistas de mercado 
(ética social); apoiar a diversidade cultural apesar do processo de globalização mundial (ética cultural); e fornecer produtos, serviços e sistemas, com aquelas formas que são expressivas (semiótica) e coerentes com sua complexidade (estética) (ICSID, 2017).

Neste contexto, o Design não pode ser definido apenas como uma ferramenta para o desenvolvimento de produtos de consumo funcionais e inovadores, mas é visto cada vez mais como um processo para mudanças radicais no desenvolvimento de serviços, sistemas e ambientes, que sustentam estilos de vida e hábitos de consumo mais sustentáveis. Este novo papel do designer, como conectores e facilitadores, como produtores de qualidade, como visualizadores e visionários, como futuros construtores (ou co-produtores) (MANZINI, 2009), tem potencial para contribuir na regeneração do tecido urbano, alcançado cidades mais habitáveis e sustentáveis como buscam ser as cidades criativas.

\subsection{Economia criativa}

O interesse pela economia criativa tem crescido em importância nas últimas décadas em função de seu potencial futuro tanto nos aspectos sociais e culturais como nos aspectos econômicos. Esta transição começou a ocorrer na década de 70, especialmente nas nações predominantemente industriais, com a passagem de uma base mais orientada à fabricação para uma base de serviços (POWELL, SNELLMAN, 2004). Três importantes mudanças na economia contribuíram para essa transformação:

a) A superação da manufatura ou fabricação pelos serviços e consequente ascensão das indústrias de tecnologia e profissionais altamente qualificados como elementos importantes na economia;

b) As estruturas de gestão organizacional se tornaram mais horizontais, e;

c) A maioria das atividades econômicas passou a envolver mais conhecimento intensivo que no passado, tanto na quantidade de informações processadas quanto na complexidade de seu processamento (HOUSTON et al, 2008).

O conceito de economia criativa teve origem no termo indústria criativa, inspirado no projeto Creative Nation, desenvolvido pelo governo australiano em 1994. Esse projeto teve como objetivos definir a importância do trabalho criativo, identificar a sua contribuição para a economia do país e definir o papel das tecnologias como aliadas da política cultural ampliando o espaço das indústrias consideradas criativas. A indústria criativa ganhou maior relevância ao fazer parte das políticas definidas pelo Department for Culture, Media and Sport (DCMS), do Reino Unido, com a criação do Creative Industries Unit and Task Force, em 1997.

O termo "economia criativa" apareceu em 2001 no livro de John Howkins sobre o relacionamento entre criatividade e economia. De acordo com o autor, a criatividade não é uma coisa nova e nem a economia o é, mas o que é nova é a natureza e a extensão da relação entre elas e a forma como combinam para criar extraordinário valor e riqueza. A economia criativa se assenta sobre a relação entre a criatividade, o simbólico e a economia. Assim, economia criativa é o conjunto de atividades econômicas que dependem do conteúdo simbólico - nele incluído a criatividade como fator mais expressivo para a produção de bens e serviços (HOWKINS, 2002). A economia criativa ainda é um conceito em evolução, apresentando diferentes definições e formas de mensuração.

A abordagem das Nações Unidas (2010) para as indústrias criativas se apoia em ampliar o 
conceito de "criatividade", passando-o de atividades que possuem um sólido componente artístico para "qualquer atividade econômica que produza produtos simbólicos intensamente dependentes da propriedade intelectual, visando o maior mercado possível". A figura 1 apresenta a classificação das indústrias criativas, incluindo o Design, produtos audiovisuais, novos meios de informação, artes do espetáculo, produção editorial e artes visuais.

Figura 1: Modelo de indústrias criativas

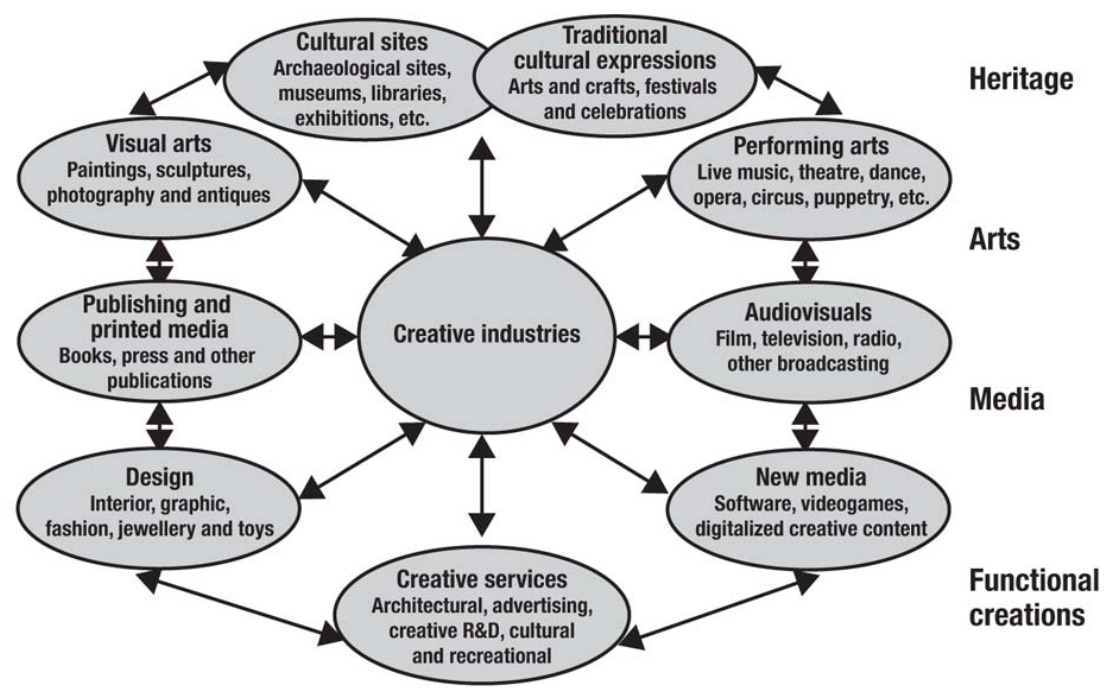

Fonte: Figure 1.3 - Classification of creative industries in (ONU, 2010 The Creative Economy Report 2010)

De acordo com Landry (2000) atualmente muitas das cidades do mundo enfrentam períodos de transição em grande parte provocada pelo vigor de uma nova globalização. Em áreas como na Ásia, as cidades estão a crescer, enquanto em outras, como na Europa, as velhas indústrias estão a desaparecer e o valor acrescentado nas cidades é cada vez menos criado através do que é manufaturado e mais através de capital intelectual aplicado a produtos, processos e serviços. A criação de valor em muitos setores da economia baseia-se cada vez mais sobre ativos intangíveis. A cultura é tanto impulsão quanto viabilização do desenvolvimento sustentável. Ela produz novas ideias e novas tecnologias que permitem às pessoas responsabilizarem-se por seus próprios desenvolvimentos e estimula a inovação e a criatividade. A economia criativa pode contribuir na geração de empregos, no bem-estar geral das comunidades, na autoestima individual e na qualidade de vida, resultando em um desenvolvimento sustentável e inclusivo. Desta forma, é de suma importância reconhecer o potencial dos setores cultural e criativo como impulsionadores de desenvolvimento (ONU, 2013).

A economia criativa é um dos setores da economia de mais rápida expansão a nível mundial. Além disso, o setor é altamente transformador em termos de produção de ingressos, de criação de emprego e de ganhos obtidos na exportação. O Relatório de economia criativa informa que o comércio mundial de bens e serviços criativos totalizaram U\$ 624 bilhões em 2011 e mais do que duplicou o valor no período compreendido entre 2002 e 2011. As exportações de produtos do mesmo segmento registraram aumento médio anual de $12,1 \%$ nos países em desenvolvimento e que a contribuição da indústria criativa representa, em média, 5,2\% do PIB (Produto Interno Bruto) em 40 países pesquisados pela UNESCO (ONU, 2013). 
No Brasil, o último mapeamento da indústria criativa foi realizado pela Federação das Indústrias do Rio de Janeiro (FIRJAN, 2016), no qual apresenta as categorias ou áreas criativas que agrupam todos os segmentos ligados à indústria criativa conforme a figura 2:

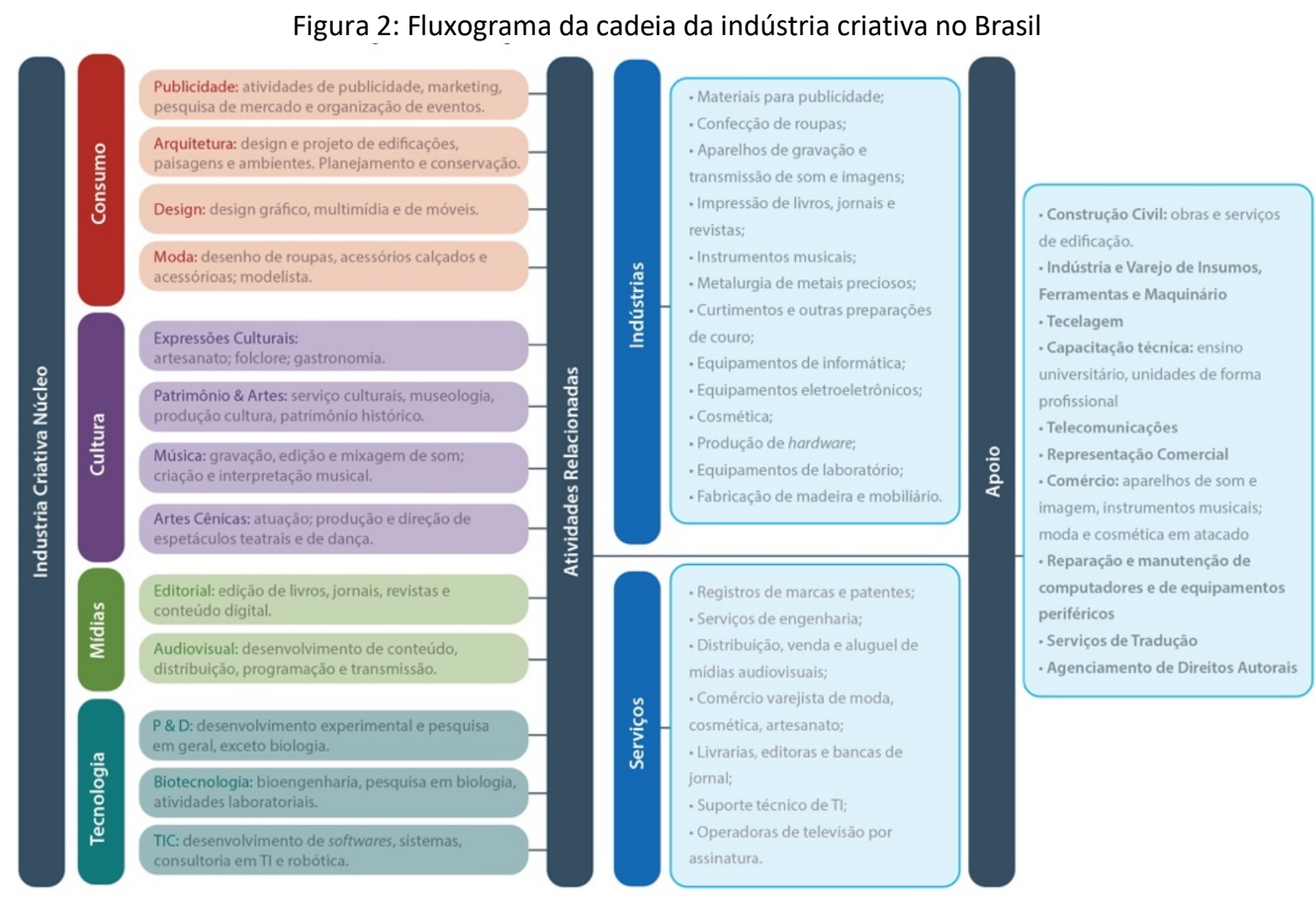

Fonte: Mapeamento da indústria criativa no Brasil (SISTEMA FIRJAN, 2016)

A partir do mapeamento realizado pela FIRJAN podemos identificar quatro categorias ou áreas criativas que agrupam todos os segmentos ligados à indústria criativa. Essas quatro categorias ou áreas criativas são: consumo, cultura, mídias e tecnologia, colocando, no caso do consumo, os segmentos: publicidade, arquitetura, Design e moda. Na categoria de cultura, considera os segmentos: expressões culturais, patrimônio e artes, música e artes cênicas. Enquanto que, na categoria mídias, os segmentos editorial e audiovisual. Por último, na categoria tecnologia, considera os segmentos: pesquisa e desenvolvimento (P\&D), biotecnologia e tecnologias da informação e da comunicação (TIC).

O Relatório de mapeamento das indústrias criativas no Brasil apresenta uma estimativa de participação do PIB criativo, em relação ao PIB Total (2004-2013), que passa de 2,09\%, em 2004, para 2,60\%, em 2013. No período 2013-2015 estima-se que as maiores participações da indústria criativa nos PIBs estaduais foram em São Paulo (3,9\%), Rio de Janeiro (3,7\%) e Distrito Federal $(3,1 \%)$. Dentre as 27 unidades da Federação, 18 mantiveram ou aumentaram a participação do PIB Criativo no período 2013-2015, o que consolida a indústria criativa como área estratégica, com visão disseminada por todo o país (FIRJAN, 2016).

No Brasil, o volume de empresas cujo principal insumo de produção são as ideias é composto por 239 mil estabelecimentos (RAIS, 2015). Em 2015, o país tinha 851,2 mil profissionais criativos formalmente empregados, frente aos 850,4 mil, registrados em 2013 . Esse crescimento 
evidencia o papel estratégico dos profissionais criativos na atividade produtiva, considerando os desafios enfrentados pela economia brasileira no mesmo período, quando foram extintos 900 mil postos de trabalho, o que representa redução de $1,8 \%$ no estoque total de trabalhadores formais (FIRJAN, 2016). Estes resultados demonstram que a economia criativa no Brasil é bastante expressiva e coloca o país entre os grandes produtores de criatividade do mundo. Devido a este potencial, em 2011 foi criada a Secretaria da Economia Criativa sob o comando do Ministério da Cultura, visando conduzir a formulação implantação e o monitoramento de políticas públicas para o desenvolvimento local e regional, priorizando o fomento aos profissionais e a micro e pequenas empresas do setor criativo no país. O Ministério da Cultura defende que a economia criativa possui dinâmica própria e, por isso, desconcerta os modelos e coloca o conceito como a economia do intangível, do simbólico. Este setor da economia alimenta-se dos talentos criativos, que se organizam individual ou coletivamente para produzir bens e serviços criativos.

\subsection{Cidade criativa}

As cidades são atores sociais complexos e de múltiplas dimensões (CASTELLS e BORJA, 1996), à medida que o planeta se torna mais urbano, as cidades precisam se tornar mais inteligentes e encontrar novas formas para gerir a crescente complexidade da vida urbana (RIZZO et al, 2015). A cidade possui um recurso crucial: suas pessoas (LANDRY, 2000) e pode ser descrita como uma estrutura econômica (uma economia), uma comunidade de pessoas (uma sociedade), um ambiente projetado (um artefato), um ambiente natural (um ecossistema) governados por um conjunto de políticas (um governo) (BIANCHINI; LANDRY, 1995). Landry (2000) apresenta a criatividade em seu sentido mais amplo, considerando que toda forma de criatividade pode fazer alguma diferença positiva para as cidades e contribuir na resolução de seus problemas.

Uma cidade criativa é um complexo urbano onde as atividades culturais de várias áreas são uma componente integral do funcionamento econômico e social da cidade (ONU, 2010). As cidades criativas utilizam seu potencial criativo de várias formas e tendem a ser construídas sobre uma sólida infraestrutura social e cultural, com altas concentrações de emprego criativo, mão-deobra altamente qualificada e flexível e cultura empreendedora, aplicada a fins econômicos e sociais.

A ideia de cidade criativa surge pela primeira vez no final da década de 1980, num momento em que as cidades sofriam reestruturações ao nível do comércio local, com a mudança desse comércio para outras zonas do globo, mais precisamente para leste (ONU, 2010). O conceito de cidade criativa contribui na maneira como as cidades em transformação podem pensar, planejar e agir com recurso à criatividade. A especificidade de cada local, em termos culturais, pode ajudar a revigorizar e a revitalizar a economia dessa cidade. Essa mudança é possível, e impulsionada, sobretudo, pelas próprias pessoas e pelas empresas dessa cidade. (LANDRY,2000). Como cidade criativa, Florida (2011) refere-se à promoção da revitalização cultural, atração de indivíduos criativos, estímulo da participação social e apoio financeiro às indústrias culturais e áreas afins. Uma cidade criativa é aquela capaz de comportar certa desordem e irregularidade enquanto renova seus padrões e inventa outras práticas de convivência. Essas cidades são autênticas em sua identidade, atraem pessoas de outras regiões e mantêm sua história viva na paisagem e na memória. São lugares onde trabalhar, morar e se divertir são atividades associadas, onde as coisas acontecem e se transformam de maneira dinâmica (REIS, 2011) a partir das interações entre os diferentes agentes presentes nela. 
De acordo com Florida (2011), tratar uma cidade como criativa significa estabelecer uma segunda geração de políticas públicas ligadas à criatividade e à inovação urbana, apoiada em uma atitude tolerante, que valorize a diversidade social e cultural, num esforço conjunto com vistas a fomentar a capacidade de investigação e de desenvolvimento de produtos tecnológicos, e atrair e fixar de talentos que contribuam para o desenvolvimento da cidade, os chamados "membros da classe criativa". Diversos países, regiões e cidades europeias têm desenvolvido programas e políticas para estimular e desenvolver as indústrias criativas e inovadoras, investindo mais em criatividade, conhecimento e tecnologia (BONTJE; MUSTERD, 2009).

Caragliu et al (2009) apresenta resultados de pesquisas que apontam taxas mais altas de prosperidade urbana em cidades onde há elevado percentual de força de trabalho educada e profissionais criativos. A contribuição do setor criativo no crescimento econômico das cidades pode ser medido em termos da contribuição direta do setor para o valor agregado, rendas e emprego; e também pelos efeitos indiretos, como por exemplo, pelos gastos dos turistas que visitam a cidade bem como a atração de investimento estrangeiro. Seul, Barcelona, Berlim, Austin, Bogotá, Melbourne e Londres são alguns dos exemplos de cidades criativas. Em Londres, por exemplo, as indústrias culturais e criativas são o segundo setor na economia desta cidade e entre o período de 1995 e 2001, as suas indústrias criativas cresceram de uma forma mais rápida do que qualquer outra indústria, com a exceção de serviços financeiros e negócios, tendo contribuído com um aumento entre $20 \%$ e $25 \%$ de emprego nesse período. A proporção de empregos no Reino Unido que fazem parte da economia criativa também aumentou, entre 2014 e 2015: de $8,8 \%$ para $9,2 \%$. (ONU, 2010).

\subsection{Classe criativa}

Uma classe corresponde a um grupo de pessoas que compartilham interesses e costumam pensar, sentir e comportar-se de modo semelhante; o que determina essas semelhanças é, antes de mais nada, a atividade econômica, o que fazem para ganhar a vida. Cada vez mais pessoas estão exercendo trabalhos criativos para ganhar a vida (FLORIDA, 2011). Classe criativa pode ser definida como um grupo formado por pessoas que agregam valor econômico por meio de sua criatividade. A principal diferença entre a classe criativa e outras classes está relacionada ao que ela é paga para fazer. Os membros da classe trabalhadora e da classe de serviços recebem sobretudo para executar de acordo com um plano. Já os da classe criativa ganham para criar e têm muito mais autonomia e flexibilidade do que as outras duas classes. A classe criativa é formada por indivíduos das ciências, das engenharias, da arquitetura e do design, da educação, das artes plásticas, da música e do entretenimento, cuja função econômica é criar novas ideias, novas tecnologias e/ ou novos conteúdos criativos. Todos os membros da classe criativa compartilham o mesmo éthos criativo, que valoriza a criatividade, a individualidade, as diferenças e o mérito. Para esses indivíduos, todos os aspectos e todas as manifestações da criatividade - tecnológicas, culturais e econômicas - estão interligados e são inseparáveis (FLORIDA, 2011). O autor enfatiza a importância do aspecto humano à definição de cidade criativa, que concentra classes de trabalhadores envolvidos no desenvolvimento de novas tecnologias e conteúdos criativos (classe criativa). "Hoje, ter acesso a pessoas talentosas e criativas, está para os negócios assim como ter acesso a carvão e minério de ferro estava para a siderurgia" (FLORIDA, 2011, p. 06).

A classe criativa é a classe que mais cresce nesta era, cerca de $30 \%$ dos indivíduos economicamente ativos nos Estados Unidos pertencem a essa nova classe. As cidades com maior concentração da classe criativa apresentam um melhor desempenho econômico (MARTIN-BRELOT 
et al, 2010). Entretanto, seu impacto não é restrito ao aspecto econômico, mas à toda vida urbana, em função da sua participação na regeneração da infraestrutura, no estímulo à cena cultural e sua preservação, no envolvimento em questões sociais e de governança, entre outros (BOYLE, 2006). Os princípios da classe criativa são muito diferentes: individualidade, liberdade de expressão e abertura à diferença. A característica que mais representa o estilo de vida da classe criativa é a busca por experiências, principalmente aquelas que refletem e reforçam sua identidade como indivíduos criativos. Uma experiência pode estimular mais as faculdades criativas do que um produto ou serviço e essa tendência reflete a formação de um estilo de vida mais dinâmico e experiencial que está surgindo na nova economia. Também seu status e identidade estão menos relacionados aos bens que possuem e mais às experiências que vivem (FLORIDA, 2011). Os integrantes da classe criativa se interessam por locais com sinais visíveis de diversidade, como a mistura entre diferentes raças, etnias, orientações sexuais, níveis de renda, estilos de vida, além da continuidade entre passado e presente e laços sociais (LAWTON et al, 2013). Os criativos também valorizam as atividades culturais oferecidas nas ruas, como música, pequenas galerias e artistas locais, aglomerados de cafés e bistrôs e gostam de praticar esportes ao ar livre, tanto os tradicionais quanto os mais radicais (FLORIDA, 2011).

As indústrias criativas e de alta tecnologia têm papel crucial no crescimento urbano a longo prazo e, com o crescimento no número de ocupações criativas, empresas e cidades se orientam a atração de pessoas criativas. Embora a presença dos criativos não garanta o desempenho urbano, em uma economia globalizada e em que há cada vez mais a utilização intensiva de conhecimento, ela pode determinar cada vez mais o sucesso das cidades (CARAGLIU et al, 2009).

\subsubsection{Fatores de atração da classe criativa}

Os criativos utilizam uma série de fatores na hora de decidir onde trabalhar e viver, mas principalmente demonstram um afastamento das comunidades empresariais tradicionais e se dirigem a lugares denominados como centros criativos. Os indivíduos criativos, por sua vez, não se concentram onde estão os empregos. Eles se reúnem em centros de criatividade e onde gostam de viver (FLORIDA, 2011). Em geral os fatores atrativos incluem diversidade cultural, ambiente acolhedor e amigável, comunidade com mente aberta, qualidade de vida, estilo de vida, envolvimento em questões sociais, custo de habitação, densidade e forma urbana, segurança, espaços verdes, recursos naturais, transporte público, limpeza, tempo e localização (DARCHEN; TREMBLAY, 2010). Na dimensão do capital humano, a cidade deve considerar atrair e reter recursos de fora, como profissionais talentosos e altamente qualificados, além de estimular empresas inovadoras, investidores e empreendedores com o capital financeiro e humano para abrir novos negócios na área (NEIROTTI et al, 2014).

Centros criativos são regiões com alta concentração de resultados econômicos sob a forma de inovações e crescimento do setor de alta tecnologia, além da elevada concentração de integrantes da classe criativa. Em geral há fortes sinais de vitalidade regional generalizada, com crescimento populacional e das taxas de emprego. Eles oferecem um ecossistema integrado em que todas as formas de criatividade podem ser desenvolvidas. As pessoas da classe criativa escolhem viver nesses locais e são seguidas pelas empresas ou criam suas próprias empresas (FLORIDA, 2011). Os estudos de Qian (2010) apresentam alguns fatores que influenciam na atração de talentos conforme figura 3:

Figura 3: Fatores de influência da distribuição geográfica de talentos. 


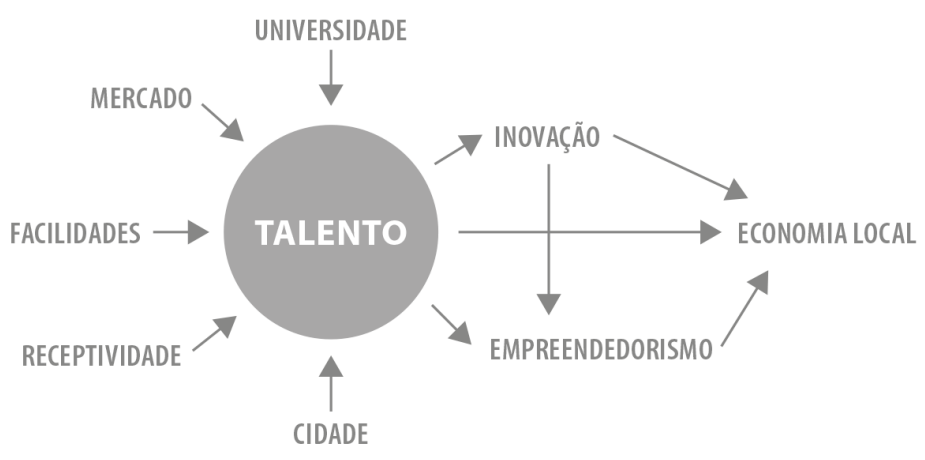

Fonte: Qian (2010).

Florida (2011) estabeleceu três variáveis principais como alicerces para uma cidade criativa, os chamados 3Ts - tecnologia, talento e tolerância:

- Tecnologia: se refere ao desenvolvimento econômico-tecnológico proporcionado pela inovação tecnológica levando a um crescimento econômico, importância de setores como software e engenharia.

- Talento: se refere ao capital humano, mensurando a disponibilidade e qualidade dos recursos humanos. Uma mão-de-obra qualificada é capaz de criar novos conhecimentos. Um fator importante para elevar o nível de talento seria a presença de universidades e centros tecnológicos, pois os mesmos são catalisadores da criatividade.

- Tolerância: responsável pela atração de diversos tipos de ideias, pessoas de variedades étnicas diversas (abertura à migração e imigração), formação socioeconômica status social e orientação.

Tecnologia é o que permite ao capitalismo se revolucionar constantemente, assegurando a sua vitalidade; talento é o segundo fator, pois os trabalhadores do conhecimento não apenas aperfeiçoam os meios de produção existentes, como também criam novos produtos e mercados; a tolerância é importante porque talento é móvel, ele flui para os lugares mais acolhedores. Se colocados individualmente, tais fatores são necessários, mas insuficientes. A fim de atrair a classe criativa, gerar inovação e crescimento econômico, os 3Ts devem coexistir mutuamente (FLORIDA, 2011).

Figura 4: Variáveis principais para uma Cidade Criativa.

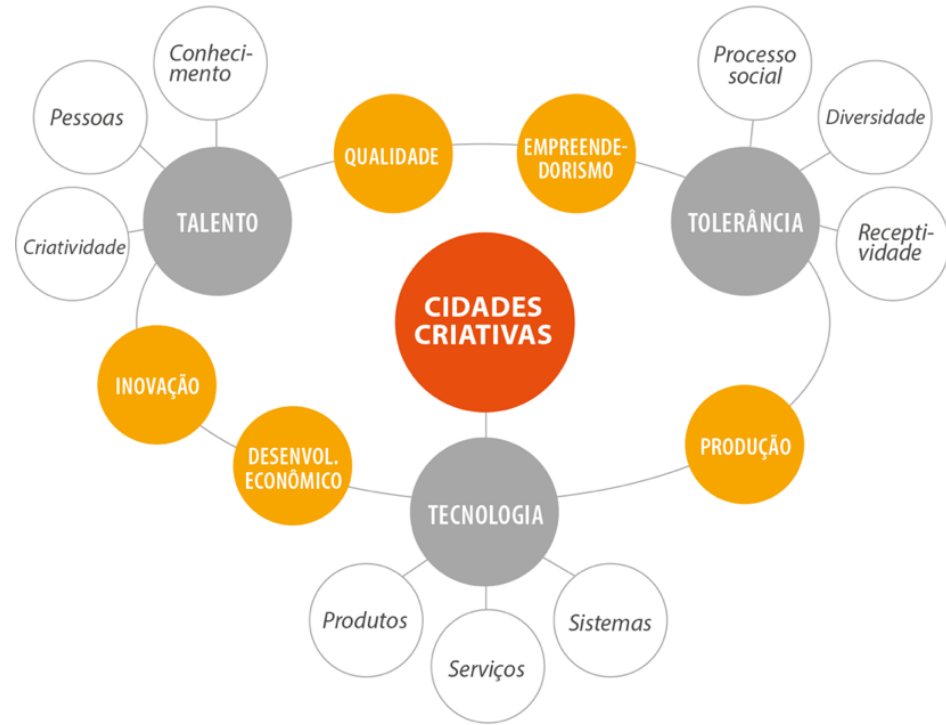

Fonte: Elaborado pela autora com base no Modelo 3Ts de cidades criativas. 


\section{Artigo Completo}

\section{O potencial de Florianópolis como cidade criativa}

Localizada na região sul do Brasil, Santa Catarina possuí em torno de 6,8 milhões de habitantes, sua capital Florianópolis é a segunda cidade mais populosa do estado com 469 mil habitantes, com previsão de 800 mil habitantes em 2035 (IBGE, 2016). A cidade é uma das capitais brasileiras com maior renda per capita média, tendo como principais atividades: comércio, turismo, construção civil, indústria da transformação, vestuário e tecnologia, esta última apresentando um crescimento de cerca de $20 \%$ ao ano (ICOM, 2015).

No período 2013-2015 estima-se que a participações da indústria criativa no PIB de SC tem aumentado, sendo atualmente a quarta do país, com 2,3\%. Os estados da Região Sul se destacaram na indústria criativa, com aumento dos profissionais empregados no Rio Grande do Sul, Santa Catarina e Paraná - crescimento que superou o desempenho do mercado de trabalho regional, implicando aumento da participação relativa dos trabalhadores criativos nesses estados. Santa Catarina possuí $2,1 \%$ de participação de trabalhadores criativos no mercado de trabalho, superando a média nacional (1,8\%, em 2015). Tanto no Rio Grande do Sul como em Santa Catarina, a área criativa mais relevante foi Consumo, acompanhada de perto por Tecnologia. Os segmentos criativos mais importantes foram TIC (19 mil trabalhadores), Design (16 mil trabalhadores) e P\&D (14 mil trabalhadores), que, somados, corresponderam a $47 \%$ dos empregos criativos nesses estados em 2015 (FIRJAN, 2016).

De acordo com o Índice de Cidades Empreendedoras, Florianópolis tem se destacado principalmente em capital humano e inovação: em 2014 Florianópolis liderou a primeira edição do Índice de Cidades Empreendedoras, e em 2015 e 2016 foi considerada a segunda cidade mais empreendedora, perdendo apenas para capital paulista (ICE, 2016). Na construção do Índice de Cidades Empreendedoras - ICE, foi elaborado um framework adequado à realidade do país, em sintonia com as ferramentas utilizadas por organizações internacionais, como a OCDE e consultorias especializadas. O framework está estruturado a partir de pilares, ou determinantes, que formam os rankings temáticos do relatório e são a base do índice final de cidades, conforme figura 4:

Figura 4: Indicadores para cidades empreendedoras

\begin{tabular}{|c|c|c|c|c|c|c|}
\hline \multicolumn{7}{|c|}{ DETERMINANTES } \\
\hline $\begin{array}{c}\text { AMBIENTE } \\
\text { REGULATÓRIO }\end{array}$ & $\begin{array}{l}\text { INFRAESTRU- } \\
\text { TURA }\end{array}$ & MERCADO & $\begin{array}{l}\text { ACESSO } \\
\text { A CAPITAL }\end{array}$ & INOVAÇĀO & $\begin{array}{l}\text { CAPITAL } \\
\text { HUMANO }\end{array}$ & $\begin{array}{l}\text { CULTURA EM- } \\
\text { PREENDEDORA }\end{array}$ \\
\hline $\begin{array}{l}\text { Tempo de } \\
\text { Processos }\end{array}$ & $\begin{array}{l}\text { Transporte } \\
\text { Interurbano }\end{array}$ & $\begin{array}{c}\text { Desen- } \\
\text { volvimento } \\
\text { Econômico }\end{array}$ & $\begin{array}{c}\text { Capital } \\
\text { Disponivel via } \\
\text { Dívida }\end{array}$ & Inputs & $\begin{array}{c}\text { Mão de Obra } \\
\text { Básica }\end{array}$ & $\begin{array}{c}\text { Potencial para } \\
\text { empreender } \\
\text { com alto } \\
\text { impacto }\end{array}$ \\
\hline $\begin{array}{c}\text { Custo de } \\
\text { Impostos } \\
\text { Complexidade } \\
\text { Tributária }\end{array}$ & $\begin{array}{l}\text { Condições } \\
\text { Urbanas }\end{array}$ & $\begin{array}{c}\text { Clientes Poten- } \\
\text { ciais }\end{array}$ & $\begin{array}{c}\text { Acesso a Capi- } \\
\text { tal de Risco }\end{array}$ & Outputs & $\begin{array}{c}\text { Mão de Obra } \\
\text { Qualificada }\end{array}$ & $\begin{array}{l}\text { Imagem do } \\
\text { Empreendedo- } \\
\text { rismo }\end{array}$ \\
\hline
\end{tabular}

Fonte: Índice de Cidades Empreendedoras - ICE, 2016.

Florianópolis continua sendo um exemplo de planejamento e da importância dos 
formuladores de políticas públicas para o desenvolvimento econômico, institucional e social, em uma história que começou há mais de 30 anos, com foco intenso na formação de boas escolas e universidades (ICE, 2016). Nas últimas décadas, a cidade registrou uma mudança no seu perfil econômico; não tendo grandes indústrias, encontrou no setor de tecnologia uma atividade econômica que se identificou com o perfil da cidade, respeitando os elementos naturais da llha e contribuindo o desenvolvimento local. A cidade possuí cerca de 600 empresas de tecnologia, dez centros e institutos de pesquisa e desenvolvimento, três universidades públicas e uma privada, incubadoras como CELTA e MIDI Tecnológico, além dos parques tecnológicos Alpha e Sapiens Parque. O setor de tecnologia tem um crescimento de $20 \%$ ao ano na economia local (ICOM, 2015) e a cidade é a segunda maior do país em proporção de empresas de tecnologia em relação ao total, com 2,5\%, enquanto a média nacional esta em torno de 1,7\% (RAIS, 2015) além de possuir uma média de 19,26 mestres e doutores em Ciências e Tecnologia para cada 100 empresas (CNPq; RAIS, 2015/2016). Atualmente, as empresas de tecnologia formam uma das atividades que mais fatura e mais paga Imposto Sobre Serviços (ISS) no município. Fazendo um paralelo com as variáveis necessárias a uma cidade criativa de acordo com Florida (2011), podemos identificar o quanto Florianópolis se sobressaí no setor de Tecnologia a nível nacional, bem como a sua importância na economia e desenvolvimento local.

O talento é abordado por Florida (2002) a partir da teoria de capital humano. Tal variável mede a disponibilidade e qualidade dos recursos humanos. Segundo o autor, uma mão-de-obra qualificada é capaz de criar novos conhecimentos. A presença de grandes universidades é comprovadamente um fator-chave no conjunto de vantagens iniciais a uma cidade criativa. As universidades são capazes de atrair e reter talentos bem como elevar o nível de talento, pois são catalisadoras da criatividade (FLORIDA, 2011; RITTGASSZER, 2011). No tocante a educação, Florianópolis é a capital com menor taxa de analfabetismo no Brasil (IBGE, 2016). Desde a primeira edição do Índice de Cidades Empreendedoras, a capital catarinense ocupa a primeira posição no índice geral de capital humano (ICE, 2016), consequência de suas boas universidades e escolas. A nota do ENEM é a mais alta entre todas as cidades, e mais de $50 \%$ dos universitários estão matriculados em cursos de alta qualidade segundo o Inep (a média geral é $21 \%$ ). Em torno de $58,4 \%$ dos adultos possuí pelo menos o Ensino Médio completo e $28,4 \%$ dos adultos com pelo menos ensino superior completo, enquanto a média nacional é de 7,9\% (ENEM/MEC, 2014). Estes dados dizem respeito ao potencial de Florianópolis no quesito Talento, a cidade apresenta alta concentração de adultos com curso superior ou acima, se destacando nacionalmente em capital humano bem como possui uma significativa concentração de universidades, institutos de pesquisa e desenvolvimento, incubadoras e empresas de tecnologia.

A população de Florianópolis é formada por $51 \%$ pessoas que não são naturais do município e atrai diariamente 120 mil pessoas que não residem na cidade, nos levando a considerar a sua abertura à imigração. Florianópolis é considerada a capital com melhor qualidade de vida e a quarta melhor cidade do país para se viver (ONU). De acordo com o Censo Demográfico (CENSO, 2010) é a cidade com maior concentração de gays do país e destino gayfriendly no mundo (IGLTA, 2016). Os profissionais da classe criativa procuram viver em um lugar onde encontrem não apenas um trabalho, mas alternativas de estilo de vida, diversidade cultural e uma comunidade com postura tolerante (FLORIDA, 2011). As baixas barreiras para entrada de talentos e o respeito a diversidade indicam o potencial de Florianópolis na variável Tolerância nos 3Ts de Florida (2011). 


\subsection{Florianópolis, cidade criativa na Gastronomia}

A Rede de Cidades Criativas da UNESCO surgiu em 2004 e funciona como ligação entre as várias cidades pertencentes à mesma rede que trabalham em conjunto e em prol de um bem comum, tendo por premissa o desenvolvimento urbano sustentável e a diversidade cultural. 0 propósito da criação desta rede é facilitar o acesso a recursos e experiências a todos os membros da cidade como forma de promover as indústrias criativas locais e fomentar a cooperação entre países de forma a criar-se o desenvolvimento da sustentabilidade urbana (UNESCO, 2014).

A rede tem neste momento 116 membros divididos nas seguintes categorias: artesanato; design; cinema, literatura; multimídia, música e gastronomia, nesta última categoria tendo Florianópolis (SC, Brasil) como integrante desde 2014.

\section{Considerações finais}

A teoria de Florida (2011) sobre as classes e cidades criativas sugere que existe uma correlação positiva significativa entre a incidência da classe criativa em diferentes cidades e o crescimento econômico local, potencializando a regeneração e o crescimento urbano. $\mathrm{O}$ autor enfatiza a importância das dimensões econômicas imateriais do espaço urbano - a criatividade associada ao capital humano - desde o declínio das restrições físicas nas cidades e comunidades nas últimas décadas. Em seus estudos, Florida (2011) desenvolveu o primeiro modelo de classificação das cidades criativas, o qual permite identificar o perfil das atividades relacionadas aos 3Ts (Tecnologia, Talento e Tolerância). Esse modelo sugere que as classes criativas são os ativos mais importantes para geração de valor de uma região, de forma que se devem direcionar políticas públicas para atração desses profissionais para geração de economia em efeito cascata. A fim de atrair a classe criativa, gerar inovação e estimular o crescimento econômico, os 3Ts devem coexistir mutuamente. Dessa forma percebe-se a importância da identificação das cidades como um novo delineador de políticas públicas, infraestrutura, atração de profissionais e economia local. Faz-se necessário uma gestão das cidades de forma a incentivar seu potencial como cidade criativa, valorizando o potencial tecnológico, intelectual, artístico, cultural e inovador. Neste sentido, o Design como atividade projetual e criativa que é, e os designers como facilitadores, visionários e viabilizadores tem potencial na contribuição para a construção e gestão de novos cenários urbanos.

Neste estudo pode-se identificar a importância da economia criativa nos processos de desenvolvimento econômico, social e ambiental bem como o potencial de Florianópolis como cidade criativa a partir de uma investigação dos dados da cidade fazendo um paralelo com o modelo 3Ts de classificação das cidades criativas. A cidade tem como principais fatores seu bom desempenho nas três variáveis principais: Tecnologia, Talento e Tolerância. Tal desempenho está diretamente relacionado com os investimentos nas áreas de tecnologia e educação, alta concentração de universidades, centros de pesquisa, incubadoras e empresas de tecnologia bem como excelentes números na área da educação e de mão-de-obra qualificada. Florianópolis também apresenta alto nível de qualidade de vida e fortes indícios de tolerância, sendo uma cidade receptiva a imigrantes e à diversidade

Para trabalhos futuros, sugere-se a investigação de novos modelos de avaliação a serem aplicados na cidade, com a finalidade de ampliar as variáveis analisadas bem como detectar possíveis melhorias que contribuam na maximização do potencial de Florianópolis como cidade criativa visando um desenvolvimento econômico e social sustentável. 


\section{Referências}

ALENCAR, E. M. L. S. Criatividade. Brasília, DF: Universidade de Brasília, 1995.

BEST, K. Fundamentos de gestão do design. Porto Alegre: Bookman, 2012.

BIANCHINI, F.; LANDRY, C. The creative city. Londres: Demos, 1995.

BONTJE M.; MUSTARD S. Creative industries, creative class and competitiveness: Expert opinions critically appraised. Geoforum, v.40, p.843-852, 2009.

BOYLE, M. Culture in the Rise of Tiger Economies: Scottish Expatriates in Dublin and the 'Creative Class' Thesis. International Journal of Urban and Regional Research, v.30, p.403-426, 2006.

BRITISH COUNCIL. Mapping the Creative Industries: a Toolkit. Creative and Cultural Economy Series. London. 2010

CARAGLIU, A.; DEL BO, C.; NIJKAMP, P. Smart cities in Europe. In: 3rd Central European Conference in Regional Science, p. 45-59, 2009.

CASTELLS, M.; BORJA J. As cidades como atores políticos. Novos Estudos, n.45, p.152-166, 1996.

CENSO. In: IBGE, 2010. (www.ibge.gov.br)

CSIKSZENTMIHALYI, M. Creativity: The Psychology of Discovery and Invention. New York: Harper Perennial, 2013.

DARSHEN, S.; TREMBLAY, D. G. What attracts and retains knowledge workers/students: The quality of place or career opportunities? The cases of Montreal and Ottawa. Cities, v.27, p.225233, 2010.

EYSENCK, H. J. As formas de medir a criatividade. In: BODEN, Margaret A. et al. Dimensões da criatividade. Porto Alegre, RS: Artmed, 1999.

FIRJAN - FEDERAÇÃO DAS INDÚSTRIAS DO RIO DE JANEIRO. Mapeamento da Indústria Criativa no Brasil, 2016. (http://www.firjan.com.br)

FLORIDA, R. Cities and the creative class. New York: Routledge, 2002

A ascensão da classe criativa: e seu papel na transformação do trabalho, do lazer, da comunidade e do cotidiano. Porto Alegre: L\&PM, 2011.

HOUSTON, D. et al. Will attracting the "creative class" boost economic growth in old industrial regions? A case study of Scotland. Geografiska Annaler, v.90, p.133-149, 2008.

HOWKINS, J. The creative economy: How people make money from ideas. UK: Penguin, 2002.

IBGE. Instituto Brasileiro de Geografia e 2016. (https://cidades.ibge.gov.br/brasil/sc/florianopolis)

ICSID - International Council Societies of Industrial Design, 2017. (http://www.icsid.org)

ICOM. In Instituto Comunitário da Grande Florianópolis, 2015. (http://www.icomfloripa.org.br)

IGLTA. In International Gay and Lesbian Travel Association, 2016. (https://www.iglta.org)

ICE. In Índice de Cidades Empreendedoras, 2015. (http://info.endeavor.org.br)

ICE. In Índice de Cidades Empreendedoras, 2016. (http://info.endeavor.org.br) 
LANDRY, C. The creative city: a toolkit for urban innovators. Londres: Comedia and Earthscan Publications, 2000.

LAWTON, P.; MURPHY, E.; REDMOND, D. Residential preferences of the 'creative class'? Cities, v.31, p.47-56, 2013.

MANZINI, E. Viewpoint - New design knowledge. Design Studies v.30, n.1, p.4-12, 2009.

MARTIN-BRELOT, H. et al. The Spatial Mobility of the 'Creative Class': A European Perspective. International Journal of Urban and Regional Research, v. 34, p. 854-870, 2010.

NEIROTTI, P. et al. Current trends in Smart City initiatives. Cities, v.38, p.25-36, 2014.

ONU. In Creative Economy Report, 2010. (http://unctad.org) . In Creative Economy Report, 2013. (http://www.unesco.org)

POWELL, W.; SNELLMAN, K. The Knowledge Economy. Annual Review of Sociol., p.199-220, 2004.

QIAN, H. Talent, creativity and regional economic performance: the case of China. Annual Reg Sci, v.45, p.133-156, 2008.

RAIS. In Relação Anual de Informações Sociais, 2015. (http://www.rais.gov.br/)

REIS, A. C. F. Cidades criativas: análise de um conceito em formação e da pertinência de sua aplicação à cidade de São Paulo. 2011. 297f. Tese de Doutorado, Universidade de São Paulo, São Paulo, 2011.

RITTGASSZER, I. Analyzing the Creativity of the Hungarian Micro-regions. 2011

RIZZO, F.; DESERTI, A.; COBANLI, O. Design and social innovation for the development of human smart cities. Design Ecologies, p.1-8, 2015.

RUNCO, M. A. Creativity. Annual Review of Psychology, n.55, p.657-687, 2004.

TORRANCE, E. P. Teaching for Creativity. The Journal of Creative Behavior, v.6, p.114-143, 1972.

UNITED KINGDOM. DCMS. In Creative Industries Mapping Document, 1998. (http://www.gov.uk) VYGOTSKY, L. S. Pensamento e linguagem. São Paulo: Martins Fontes, 1987. 